Wohl auch Iberien (im älteren Sinn des Wortes d. i. die Mittelmeerküste Hispaniens), Ligurien und Tyrrhenien. Ein späteres Buch wird nicht citirt.

Buch IX vielleicht die Kelten Hispaniens, Galliens, Ober-

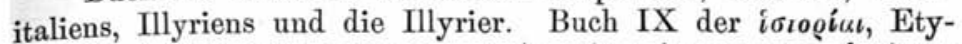

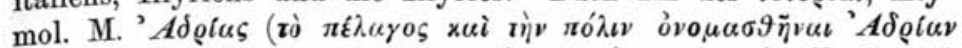

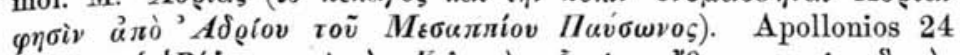

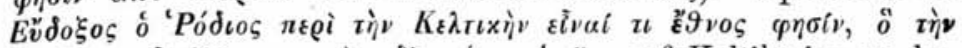

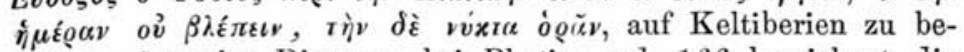
ziehen: Antonius Diogenes bei Photios cod. 166 bezeichnet die Albinos als Einwohner einer Stadt Iberiens (im späteren Sinn).

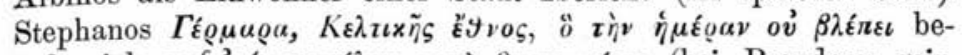
ruft sich auf "Aọ ausc. nicht zu finden).

Würzburg.

G. F. Unger.

\title{
Zur Schrift vom Staate der Athener.
}

P. 15 Z. 10 ist jedenfalls statt der Kenyonschen Ergänzung

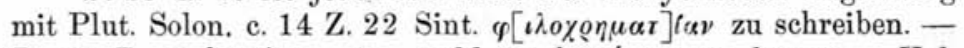

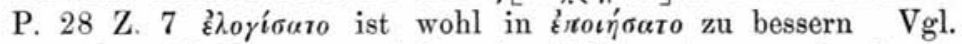
cap. 13 p. 32 Z. 1 v. u. Aristoteles liebt es den unterbrochenen Faden mit denselben Worten wieder aufzunehmen, mit welchen er vor dem eingeflochtenen Excurse abgebrochen so: p. 36 Z. 6

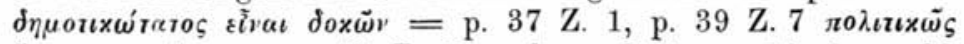

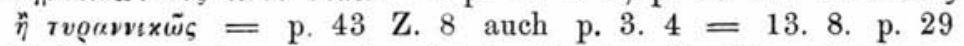

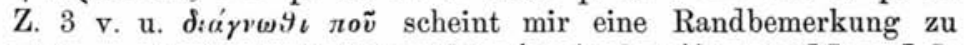

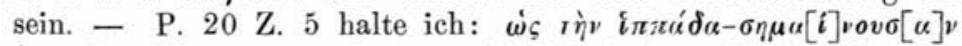
für eine Glosse zu roṽzo. - P. 35. 2 ist mit den Berliner Fragmenten col. I ${ }^{6}$ Z. 10 ed. Diels $\omega_{0}^{3}[x u i]$ nicht $\omega[\sigma r \varepsilon]$ zu ergänzen. Dieselben Fragmente hatten, wie sich aus der Berech-

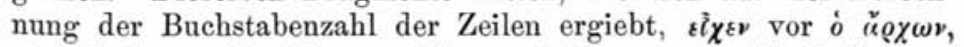
eine Stellung die ich vorziehen würde. - P. 41 Z. 1 v. u. verlangt die Zeitrechnung die Einschiebung von $\langle\mu \varepsilon r \dot{\alpha}\rangle$ vor:

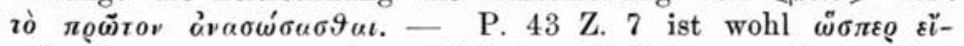
$\eta[\tau \alpha \iota]$ zu ergänzen vgl. p. 13 Z. 8 , p. 28 Z. 3. - P. 46 Z. 1 ist der Vorschlag Heerwerdens zwischen ${ }_{\boldsymbol{i}} \tilde{\eta} \varsigma$ und $\gamma \alpha \mu \varepsilon \tau \tilde{\eta} \tilde{\eta}_{\varsigma}$ ein

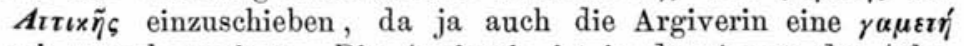
sei, zurückzuweisen. Die Argiverin ist in den Augen des Atheners keine legitime Ehefrau keine $\gamma \propto \mu \varepsilon \eta^{\prime}$ (s. auch p. 11 Z. 4, Hegesistratos ein vógọ (Herodot V. 94).

Innsbruck.

\section{Radinger.}

